\title{
Measuring the Effectiveness of Planned Teaching Programme on Lamaze Technique in terms of Knowledge and Skill of Staff Nurses Working in Antenatal Ward and Labour Room in a Maternity Hospital of Kashmir
}

\author{
Tabssum Irshad $^{1}$, Dr. Manju Chhugani ${ }^{2}$, Eke Lama Tamang ${ }^{3}$ \\ ${ }^{1}$ Staff Nurse, Sher-i-Kashmir Institute of Medical sciences, Soura, Srinagar, Kashmir, India \\ ${ }^{2}$ Professor, Principal, Rufaida College of Nursing, Jamia Hamdard, New Delhi, India \\ ${ }^{3}$ Tutor, Rufaida College of Nursing, Jamia Hamdard, New Delhi, India
}

\begin{abstract}
Birth is a time of physical and emotional crisis for woman, her child and her family. It requires collaborative care between the obstetric team, the pregnant woman and the couple Lamaze technique, often referred to as Lamaze, it is a childbirth preparation technique developed in the 1940s by French Obstetrician Dr. Fernand Lamaze as an alternative to the use of medical intervention during child birth. The goal of Lamaze is to increase a mother's confidence in her ability to give birth. The main objectives of the study were to evaluate the effectiveness of a Planned Teaching Programme (PTP) on Lamaze technique, in enhancing the knowledge and skill of staff nurses the study using a pre-post Experimental Design. 30 participants were selected using total enumerative sampling technique. A pre-test was conducted to assess the knowledge and skill regarding Lamaze technique structured knowledge questionnaire and structured observation checklist respectively. A verbal introduction regarding Lamaze technique was given with help of power point presentation followed by demonstration of Lamaze technique. The average time taken by the staff nurses to learn Lamaze technique was 1 hour. On the $7^{\text {th }}$ day of introducing the treatment variable, a post-test to assess knowledge and skill using same tools was conducted. The mean post-test knowledge (23.6) and skill (102.3) scores were higher than the mean pre-test knowledge (18.03) and skill (55.3) score at0.05 level of significance. The study findings revealed that staff nurses had low level of knowledge and skill regarding Lamaze technique and that there was improvement in the knowledge and skill of staff nurses regarding Lamaze after the administration of PTP.
\end{abstract}

Keywords: Lamaze Technique, Staff Nurses, Knowledge, Skill, Planned Teaching Program

\section{Introduction}

Birth is a time of physical and emotional crisis for woman, her child and her family. It requires collaborative care between the obstetric team, the pregnant woman and the couple. The goal of care is safe delivery of the mother and child and promotion of emotional fulfillment for the entire family. The woman and her family need knowledge about the components of a healthy pregnancy, the process of labour and birth and coping strategies to deal with the challenges of parenthood. Education for family members should begin before pregnancy and continue through postpartum period.

During the clinical experience, the researcher observed that due to ignorance, the mothers are not able to adjust themselves or cope with the labour pains. They scream and become exhausted much earlier using their power of pushing the fetus before time, leading to prolong and complicated labour. Due to apprehension they are not able to comply with the instructions i.e. to relax and breathe properly in between the contractions of uterus. Personal enquiry of the researcher revealed that if they were instructed earlier, they would comply better with the instructions.

Fear induces restriction of the circulation of the blood through the uterus, thereby limiting in many ways efficient to the mechanism of parturition adding to its discomfort the exquisite muscle tenderness or ischemia. ${ }^{2}$

It is also identified that mothers who adopted physical relaxation measure differ significantly in their responses. So there is a need to provide comfort measures in relaxation to natural childbirth. ${ }^{3}$

A good breathing habit needs to be developed since mother and baby benefit from an optimum supply of oxygen during pregnancy and labour. She explained that slow, deep breathing aids the blood circulation and it's smooth rhythm helps mother to relax. ${ }^{4}$

A study also reported that $68-75 \%$ of mothers could relax spontaneously in an experimental group who are taught antenatal exercises, whereas none in the control group. More mothers in the experimental group had a normal delivery because they took Antenatal exercises. ${ }^{5}$

One of the study evaluated the effectiveness of the Lamaze method, a method of Natural childbirth that implies having one's baby the natural way, that is, in a relaxed attitude, without anesthesia or analgesics and without any mechanical aid to birth and reported that majority (45\%) of women who were taught Lamaze method were prepared and managed well during their childbirth. ${ }^{6}$ 


\section{International Journal of Science and Research (IJSR) \\ ISSN (Online): 2319-7064 \\ Index Copernicus Value (2013): 6.14 | Impact Factor (2014): 5.611}

The study has been conducted in Kashmir, India. The researcher belongs to the same state as well as community and admits that the women here are overworked because of joint family system. The women during first 10-15 years of marriage perform all the house hold chores At the same time most of the women work in addition to earn (office, hand skill etc.) There is no custom of hiring domestic help. It is true that most of the Indian mothers especially in Kashmir are overworked. They need rest and proper health education during pregnancy. The Lamaze exercise will help them to get over the tiredness through the exercise of passive relaxation during the antenatal period. Teaching of breathing and relaxation exercises to mothers is essential for selfadjustment with the contraction of uterus during labour thereby resulting in safe and natural delivery and also ensuring less operative interference.

Since there is no such provision for providing advice during intranatal period, mothers are not prepared mentally or physically to deal with the intranatal happenings of pregnancy.

Hence, the researcher felt that there is a need to find out the effectiveness of Lamaze exercise taught to staff nurses in terms of improving their knowledge and skill pertaining to Lamaze method, which can further contribute effectively in reducing fetal and maternal complications during childbirth.

\section{Objectives of the Study}

The objectives of the study were to evaluate the effectiveness of a Planned-teaching programme (PTP) in enhancing staff nurse's knowledge and skill on Lamaze technique

\section{Materials and Methods}

\section{Research Design}

The research design selected for the present study was One Group Pre-Test Post-Test Experimental Design:

$\mathrm{OK}_{1} \mathrm{OS}_{1}+\mathrm{X}=\mathrm{OK}_{2} \mathrm{OS}_{2}$

Whereas

$\mathbf{O K}_{1} \mathbf{O S}_{1}$ stands for pre-test scores of knowledge and skill. $\mathbf{X}$ stands for Intervention (PTP)

$\mathbf{O K}_{2} \mathbf{O S}_{2}$ stands for post-test scores of knowledge and skill.

Table 1: Schematic Representation of the Research design

\begin{tabular}{|c|l|c|l|}
\hline Group & Pre-Test (Day-1) & $\begin{array}{c}\text { Treatment Day } \\
(\text { Day-1) }\end{array}$ & $\begin{array}{c}\text { POST-TEST } \\
(\text { DAY-7) }\end{array}$ \\
\hline $\begin{array}{c}\text { Staff } \\
\text { nurses }(\mathrm{n}=30)\end{array}$ & $\begin{array}{l}\bullet \text { Knowledge test } \\
\text { - Skill test }\end{array}$ & $\begin{array}{c}\text { Administration } \\
\text { of PTP }\end{array}$ & $\begin{array}{l}\bullet \text { Knowledge test } \\
\text { - Skill test }\end{array}$ \\
\hline
\end{tabular}

The dependent variable will be measured before independent variable is introduced. After 7 days, the dependent variable will be measured again the difference of which will provide the effect of the independent variable.

\section{Setting}

The present study was carried out in the Conference room of Sher-I-Kashmir Institute of Medical Sciences SKIMS, Kashmir. The population in this study comprises of all staff nurses, working in SKIMS Maternity hospital.

\section{Sample and Sample Size}

The sample for this study comprised of 30 staff nurses working in Antenatal ward and Labor room selected by total enumeration technique.

\section{Process of the Study}

The structured knowledge questionnaire and the observation checklist were developed by the researcher by her own efforts on the basis of Planned teaching programme that was to be delivered to the participants, as it was not a standardized tool, hence was formerly validated by experts before being administered. A Planned Teaching Program (PTP) on Lamaze technique was administered to the staff nurses.

The Tool - Structured Knowledge Questionnaire was submitted to seven experts from field of nursing, medicine, of which one expert was a childbirth educator.

All the experts agreed $100 \%$ to the correct response listed in the structured knowledge questionnaire. The mean percentage of agreement for items from experts was $94.6 \%$ as determined using the criteria rating scale.

The structured knowledge questionnaire was administered to 10 staff nurses in a selected hospital of New Delhi to establish the reliability. The Kuder Richardson (KR-20) formula was used to calculate the reliability coefficient. The value of ' $r$ ' was found to be 0.91 indicating high reliability of the tool.

The Tool - Observation Checklist was given to the same seven experts along with the structured knowledge questionnaire for validation. On the suggestion of the experts some of the items were modified and reorganization of the observation checklist was done and finally the observation checklist consisted of 60 activities on Lamaze technique.

The observation checklist consisted of 60 activities. Activity if performed, a score of two was given, if partially performed a score of one was given, if not performed at all, a score of zero was given. Thus, the total score of the checklist was 120. A blueprint of the observation checklist is given in Table 3. The marking scheme was then specified i.e. a score of $80 \%$ and above was considered adequate skill

\section{Ethical Approval and Formal Permission}

Formal administrative permission had been obtained from the administration of selected maternity hospital, Kashmir. Final study was conducted between $19^{\text {th }}$ December 2011 and $2^{\text {nd }}$ January 2012. 


\section{International Journal of Science and Research (IJSR) \\ ISSN (Online): 2319-7064 \\ Index Copernicus Value (2013): 6.14 | Impact Factor (2014): 5.611}

Self-Introduction and introduction to the nature and objectives of study were given to staff nurses working in Antenatal Ward and Labor Room to obtain free and frank response. Confidentiality of their responses was assured. 30 staff nurses were selected using total enumerative sampling technique as planned in the research methodology.

\section{Data Collection}

On day 1, a pre -test to assess the knowledge and skill regarding Lamaze technique was administered. Then a verbal introduction regarding Lamaze technique was given with help of power point presentation followed by demonstration of the Lamaze technique. The average time taken by the staff nurses to learn Lamaze technique was 1 hour. After introducing the treatment variable, a post -test to assess knowledge and skill was administered through structured knowledge questionnaire and observation checklist for return demonstration respectively on day 7 .

\section{Results (Data Analysis)}

\section{Section 1}

Table 2: Frequency and Percentage Distribution of the Demographic Characteristics of Sample subjects, $n=30$

\begin{tabular}{|c|c|c|c|}
\hline $\begin{array}{c}S . \\
\text { No }\end{array}$ & Characteristics & Frequency & Percentage \\
\hline 1. & $\begin{array}{l}\text { Age } \\
\text { a) } 21-25 \mathrm{yrs} \\
\text { b) } 26-30 \mathrm{yrs} \\
\text { c) } 31-35 \mathrm{yrs} \\
\text { d) More than } 35 \mathrm{yrs}\end{array}$ & $\begin{array}{c}1 \\
4 \\
9 \\
16\end{array}$ & $\begin{array}{c}3.30 \% \\
13.3 \% \\
30 \% \\
53.3 \%\end{array}$ \\
\hline 2. & $\begin{array}{l}\text { Professional qualifications } \\
\text { a) General Nursing and } \\
\text { Midwifery } \\
\text { b) B.Sc Nursing } \\
\text { c) Post Basic B.Sc Nursing } \\
\text { d) M.Sc Nursing or other. }\end{array}$ & $\begin{array}{c}21 \\
1 \\
8 \\
0\end{array}$ & $\begin{array}{c}70 \% \\
3.3 \% \\
26.6 \% \\
0 \%\end{array}$ \\
\hline 3. & $\begin{array}{l}\text { Experience in Hospital } \\
\text { a) } 1-3 \text { yrs } \\
\text { b) } 4-6 y r s \\
\text { c) } 7-9 y r s \\
\text { d) More than } 10 \mathrm{yrs}\end{array}$ & $\begin{array}{c}1 \\
4 \\
5 \\
20 \\
\end{array}$ & $\begin{array}{l}3.30 \% \\
13.3 \% \\
16.6 \% \\
66.6 \% \\
\end{array}$ \\
\hline 4. & $\begin{array}{l}\text { Experience in Ante- } \\
\text { natal/Labour ward } \\
\text { a) } 1-3 \mathrm{yrs} \\
\text { b) } 4-6 \mathrm{yrs} \\
\text { c) } 7-9 \mathrm{yrs} \\
\text { d) More than } 10 \mathrm{yrs} \\
\end{array}$ & $\begin{array}{l}9 \\
9 \\
9 \\
3\end{array}$ & $\begin{array}{l}30 \% \\
30 \% \\
30 \% \\
10 \%\end{array}$ \\
\hline 5 & $\begin{array}{l}\text { In service education program } \\
\text { a) Yes } \\
\text { b) No }\end{array}$ & $\begin{array}{c}3 \\
27\end{array}$ & $\begin{array}{l}10 \% \\
90 \%\end{array}$ \\
\hline
\end{tabular}

Frequency and Percentage Distribution of the Demographic Characteristics of Sample subjects were computed (Table 2). The majority (16) $53.3 \%$ of subjects, were in the age group of above 35 years,(9) $30 \%$ were in the age group of $31-35$ years,(4) $13.3 \%$ in the age group of 26-30years and only (1) $3.30 \%$ in the age group of 21-25years.

Regarding Professional Qualification, majority (21)70\% had completed Diploma in General Nursing and Midwifery GNM,(8) 26.6\% had Post Basic B.Sc. Nursing and only (1) $3.3 \%$ completed B.Sc. Nursing.

Majority of the subjects (20) $66.6 \%$ had an experience of more than 10 years,(5) $16.6 \%$ had experience of $7-9$ years,(4) $13.3 \%$ had an experience of 4-6 years and only (1) $3.30 \%$ had an experience of 1-3 years.

(9)30\% of sample subjects had an experience of 7-9 years,(9) 30\% had an experience of 4-6 years, (9) $30 \%$ had an experience of 1-3 years and only(3) $10 \%$ had more than 10 years of experience in antenatal ward and labour room.

Only (3)10\% of the sample subjects had attended in-service education programmes on obstetrics and gynecology whereas majority (27) $90 \%$ had not attended any in-service education programme on obstetrics and gynecology.

\section{Section 2}

In Section 2 the t' value being computed was more than the table value and significant at the 0.05 level hence the difference between pre-test score and post-test score of knowledge was statistically significant.(Table3).

Table 3: Mean, Mean difference, Standard Deviation Of Difference, Standard Error of Mean Difference and ' $t$ ' value of Pre-Test and Post-Test Knowledge Score Of Staff Nurses, $\mathrm{n}=30$

\begin{tabular}{|c|c|c|c|c|c|}
\hline $\begin{array}{c}\text { Knowledge } \\
\text { test }\end{array}$ & Mean & $\begin{array}{c}\text { Mean difference } \\
(\mathrm{MD})\end{array}$ & SD .D & SE.MD & ' $\mathrm{t}$ ' value \\
\hline $\begin{array}{c}\text { Pre-test } \\
\text { Post-test }\end{array}$ & $\begin{array}{c}18.03 \\
23.6\end{array}$ & 5.6 & 2.9337 & 0.535 & 10.467 \\
\hline
\end{tabular}

' $t$ ' $($ df 29$)=2.05, p \leq 0.05 *$ significant at 0.05 level 


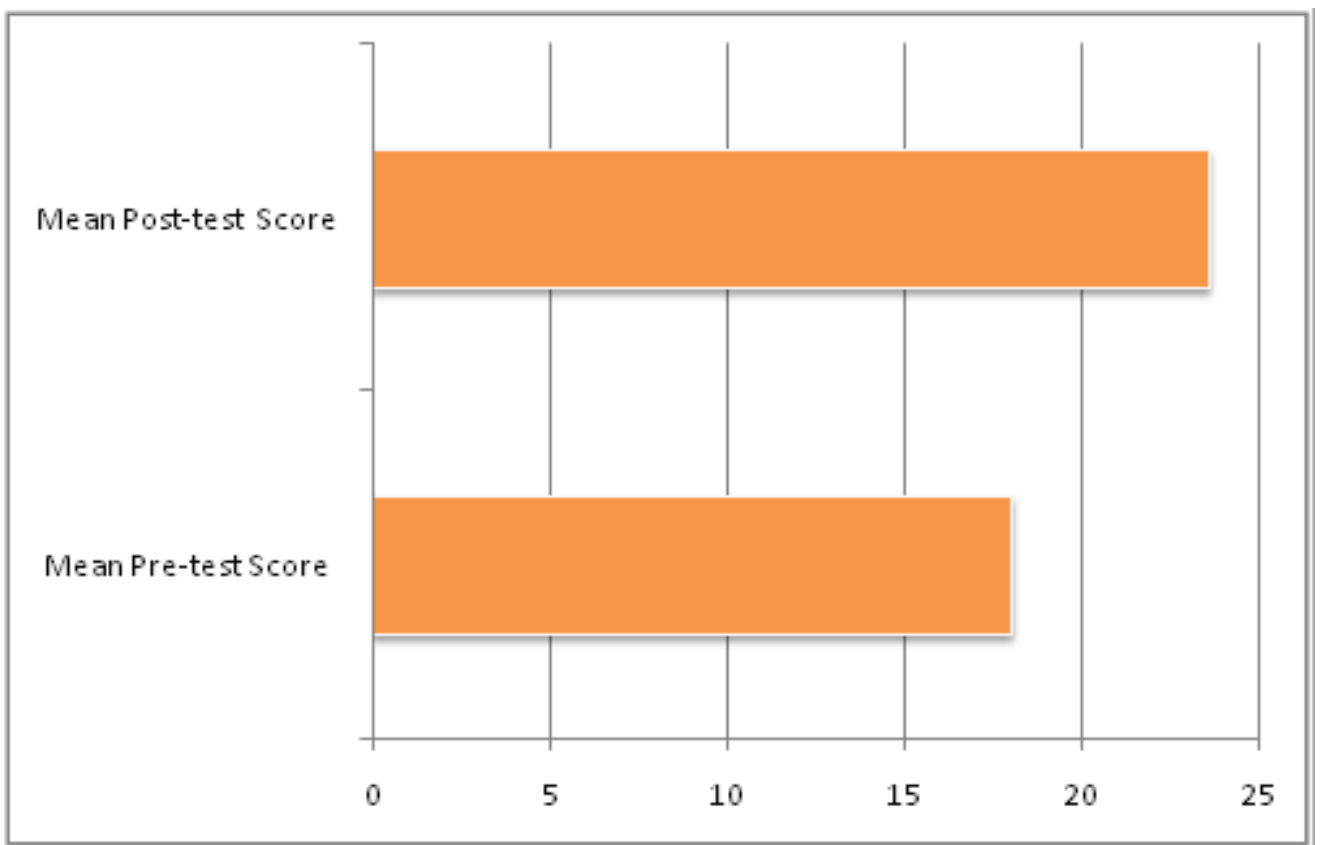

Figure 1: A Bar Diagram illustrating the Mean Pre-test and Mean Post-test Knowledge Scores of Staff Nurses

\section{Section 3}

The mean post-test skill score (102.3) was higher than the mean pre-test skill score (55.3) of staff nurses with a mean difference of 47 . The obtained mean difference was found to be statistically significant as evident from the ' $t$ ' value of pre-test and post-test skill scores(31.907) which is significantly higher than the table value of 2.05 at 0.05 level of significance, (Table 4)

Table 4: Mean, Mean Difference, Standard Deviation of Difference, Standard Error of Mean Difference and ' $t$ ' value of Pre-test and Post-test Skill Score of Staff-Nurses, $n=30$

\begin{tabular}{|c|c|c|c|c|c|}
\hline Skill Score & Mean & MEAN D & SD D & SE MD & 't' value \\
\hline Pre test & 55.3 & 47 & 8.068 & 1.473 & 31.907 \\
Post-test & 102.3 & & & & \\
\hline
\end{tabular}

' $t$ ' ( df 29) $=2.05, p \leq 0.05 *$ significant at 0.05 level

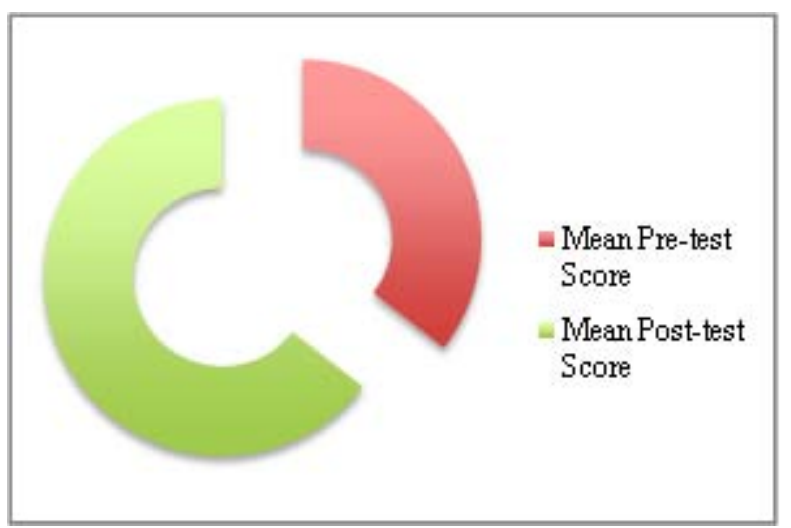

Figure 2: A Doughnut Diagram illustrating the Mean PreTest and Post-Test Skill Score of Staff Nurse

\section{Section 4}

The relationship between post- test knowledge and post-test skill of staff nurses was analyzed using Karl Pearson's 'coefficient of correlation'.
The findings reveal that the coefficient of correlation between post-knowledge and post-test skill (0.027) was not statistically significant as the ' $r$ ' value is less than the table value of .361 . Hence there is no significant relationship between post-test knowledge score and post-test skill score of staff nurses regarding Lamaze technique,

\section{Discussion and Conclusion}

The study revealed that staff nurses had low level of knowledge and skill regarding Lamaze technique as evident from the pre-test knowledge and skill scores. The findings of the present study indicated that there was improvement in knowledge and skill of staff nurses regarding Lamaze after the administration of PTP.

The findings were consistent with the findings of the study done by SK Dnazigar (1979), which showed that nurses were found to offer arbitrary and often inappropriate responses to birthing women that may inhibit well-being, due to knowledge deficit. ${ }^{7}$

The importance of improvement of knowledge and skill of staff nurses regarding Lamaze technique is supported by the study done by Amanda .M. Handin (2004) that showed that patients found the help of an experienced staff nurse with knowledge of Lamaze technique important. Many were willing to change care providers to gain support for their desire for an unmedicated birth. ${ }^{8}$

The findings were found similar to the findings of the study done by Ellen B. Buckner (2004) that reveals, 'when labor ' $n$ ' birth Nurses are asked to support an unmedicated birth, some are unprepared to assist and express concern about a woman's choice implying woman would be 'better off' with anesthesia or medication.' Further, education may give health care providers further knowledge in assisting woman who chooses unmedicated labor and birth. ${ }^{9}$ 


\section{International Journal of Science and Research (IJSR) \\ ISSN (Online): 2319-7064}

Index Copernicus Value (2013): 6.14 | Impact Factor (2014): 5.611

The study is limited only to the improvement of knowledge and skill of Staff nurses regarding Lamaze technique. No follow up was done to check if the staff nurses had been teaching the same to the antenatal women during their antenatal visits.A separate study needs to be done for the purpose and to assess the maternal and fetal outcome among antenatal women after subjecting them to Lamaze technique of child birth preparation

\section{Recommendations}

A woman generally has a vague notion that childbirth is unbearable pain and danger. To help women to have stress free, safe delivery, it becomes a professional obligation of a staff nurse to train her during her pregnancy so that she easily overcomes the painful situation and delivers safely without landing up in any fetal or maternal complication, making this event more delightful, pleasant and safe.

Staff nurses working in the antenatal ward and labour room should be able to demonstrate their ability in providing need based care including antenatal exercises. Quality nursing care depends on the skill and knowledge of staff nurses. Staff nurse must keep herself updated with the latest development and trends in her field so that she provides quality-nursing care.

Nurse educators should pay more attention towards teaching the Lamaze technique to the student nurses at their graduate and postgraduate levels. Lamaze technique should be included in the curriculum along with other antenatal exercises. Awareness needs to be generated among the student nurses regarding the importance of Lamaze technique in reducing the maternal and fetal complications during labour process. Nurse educators need to organize short-term training programme or workshops on Lamaze technique for the staff nurses working in antenatal ward and labour room.

The consumer determines quality nursing care of a hospital. Achievement of the institutional policies is based on the availability of the resources, infrastructure and development of protocols. Therefore it is very important that to practice the advanced method of antenatal exercises. i.e. Lamaze technique, the administrator should arrange for adequate resources, e.g. spacious rooms in antenatal wards and antenatal clinics (OPDs).Training programmes, in-service education and continuing education programmes on Lamaze technique should be conducted in such a way that each staff nurse gets exposure to at least one training programme during the tenure of her service.

Nursing profession recognizes the professional responsibility of broadening the body of knowledge of nursing. Research has a vital and significant role in nursing in terms of quality and cost effective service. Lamaze technique of childbirth preparation can be considered as one of the quality and cost effective services. Emphasis should be given for publication of research findings on Lamaze technique in professional journals, periodicals and books to disseminate the research-based evidence for introducing practice of Lamaze technique.

\section{References}

[1] WHO (2012) World health day. Safe mother hood division of reproductive health. WHO Geneva.

[2] Dr. Read Dick Grantly. Childbirth without Fear. April 2010.

[3] Sasan K K . Effectiveness of Comfort measures during Labour for Natural Childbirth: 1976.

[4] N Elizebeth .Birth without Violence;1976: 88-89

[5] Das Gupta M. Effect of selected Antenatal Exercises on the Nature and Outcome of Labour in Primipara Mothers during Antenatal Period in a selected hospital. May, $1983 ; 72$.

[6] Mackey M C. How to Cope with Labour: Prepare for childbirth.1995; 6(3): 24.

[7] Danzinger S K. Treatment of Women in Childbirth: Implications for Family Beginnings. American Journal of Public Health. Sept 1979; 69 (9): 895 - 901.

[8] Hardin. M. Amanda and Buckner B Ellen. Characteristics of Positive Experience for Women who have Unmedicated Childbirth. Journal of Perinatal Education. 2004; 13(4): 10-16. 